\title{
A Ausência de articulação teoría-prática nos componentes curriculares
}

\section{A Absence of theory-practice articulation in the curricular components}

\author{
Yara Pires Gonçalves, * Rita de Cássia M. Trindade Stano** \\ *Centro Universitário Toledo; **Universidade Federal de Itajubá.
}

\begin{abstract}
Resumo
O trabalho apresenta estudos realizados em um Centro Universitário Brasileiro, objetivando confrontar documentos oficiais sobre as políticas públicas relativas à teoria e à prática presentes nos componentes curriculares de cursos de natureza diversa. Quanto à relação teoria e prática nos currículos formativos foram pesquisados os discursos oficiais e o papel do docente nessa articulação, por meio da abordagem qualitativa de base filosófica dialética. Os resultados apontam a fragilidade entre a teoria e a prática, o descompasso entre o lócus de formação e o de atuação docente e lacunas no entendimento da unidade dialética (teoria e prática), refletindo nos componentes curriculares.

Palavras-chave: Ensino Superior, articulação teoria e prática, formação docente.
\end{abstract}

\begin{abstract}
The paper presents studies carried out in a Brazilian University Center, aiming to confront official documents on the public policies related to theory and practice present in the curricular components of courses of diverse nature. As for the relation theory and practice in the formative curricula, the official discourses and the role of the teacher in this articulation were investigated through a qualitative approach with a dialectical philosophical base. The results point to the fragility between theory and practice, the gap between the locus of formation and the activity of teaching, and gaps in the understanding of dialectical unity (theory and practice), reflected in the curricular components.

Keywords: Higher education, articulation theory and practice, teacher training.
\end{abstract}

\section{Introducão}

Mudanças sociais e avanços tecnológicos compõem um cenário contextual marcado por mudanças e transformações diversas. Educar para a incerteza, para uma sociedade em movimento, neste momento de interregno entre o que existe e o que ainda não se definiu (BAUMAN, 2011), dá ao professor, no âmbito educacional, papel social estratégico e exige que ele tenha uma formação adequada aos novos tempos.

A teoria e a prática têm, neste contexto, lugar privilegiado nos componentes curriculares que compõem o percurso curricular formativo dos futuros professores e profissionais de outras áreas. Teoria e prática são elementos indissociáveis, permeiam e significam os saberes oriundos das experiências sociais vivenciadas. Formam uma unidade, integram-se e são integradores dos componentes curriculares. A articulação entre eles, no ato educativo, supera a singularidade que os identifica.

A relevância do objeto de pesquisa: articulação teoria-prática nos componentes curriculares é, portanto, social, institucional e pessoal, pois se coloca como vertebradora da formação de professores e profissionais, possibilitando a geração de conhecimento e desenvolvimento nas sociedades contemporâneas.

A pesquisa desenvolveu-se em um Centro Universitário Brasileiro, no interior do Estado de São Paulo, nos cursos de Administração e Ciências Contábeis (bacharelados).

Para estudar a relação teoria e prática nos currículos formativos foram pesquisados os discursos oficiais e o papel do docente na articulação teoria-prática por meio de abordagem qualitativa (BOGDAN,1994, p. 47-51) de base filosófica dialética, com a finalidade de apreendê-lo em seus significados e sentidos.

A escolha da abordagem qualitativa, na ótica da dialética, nesta pesquisa, tomou como ponto de partida "A visão de mundo, entendida como uma percepção organizada da realidade que orienta a produção da pesquisa, se constrói através da prática cotidiana do pesquisador e das condições concretas de sua existência" (GAMBOA, 1997, p. 107).

O objetivo desta pesquisa é confrontar o discurso oficial, contido nas Diretrizes Curriculares Nacionais e Instrumento de Avaliação de Cursos de Graduação presencial e a distância, e a prática docente com a finalidade de se verificar a articulação teoria-prática nos componentes curriculares.

Deve-se ressaltar que esses documentos se constituem em parâmetros de qualidade em educação para o Ministério da Educação-MEC e nos permite inferir o que se considera qualidade do ponto de vista oficial, isto é, o que é qualidade em educação na ótica dos órgãos governamentais responsáveis e representativos da educação brasileira superior.

A título de clareza, alguns conceitos pertinentes ao tema devem ser considerados como: teoria- prática e prática e práxis. Teoria e prática são unidades de movimento, uma está contida na outra, em constante processo: "[...] contexto de que fazer, de práxis, quer dizer, de prática e de teoria” (FREIRE, 2006, p.106 “[...] 
toda prática tem um fundamento teórico e vice-versa [..] (FREIRE; SHÖR, 2006, p.12). Para Freire, teoria e prática se constituem em uma unidade dialética, indissociável.

Dentro do contexto atual, é necessário se repensar a teoria e a prática docente como práxis, como prática docente consciente, quando se almeja a transformação social, com vistas à consecução de um projeto educacional emancipatório que pressupõe a formação de sujeitos autônomos, capazes de produzir seu próprio conhecimento, de posicionar-se diante da realidade, de ter postura crítica e refletir sobre suas ações e as dos outros (GIROUX, 1997, SANTOS, 2003, FREIRE, 2004)

\section{A teoría e prática nos discursos oficiais}

A articulação da teoria-prática nos componentes curriculares tem sido foco de pesquisas e discussões no ensino superior, nos cursos de bacharelados e ou licenciaturas, no que diz respeito à sua efetiva concretização ao longo do percurso formativo dos futuros professores e profissionais de outras áreas.

Esses cursos são concebidos à luz de algumas variáveis como fundamentos epistemológicos, demandas sociais, políticas governamentais e institucionais, mercado de trabalho, mas sempre regidos por documentos oficiais, conforme exigência legal. De acordo com o objeto de pesquisa, análise da relação teoria-prática nos cursos mencionados, optou-se por confrontar os discursos oficiais expressos, dentre eles, nas Diretrizes Curriculares Nacionais, gerais e específicas por curso, e Instrumento de Avaliação de Cursos de Graduação presencial e a distância, afeto ao Sistema Nacional de Avaliação da Educação Superior-SINAES (2015), considerados parâmetros de qualidade oficial para as políticas públicas vigentes e seu impacto na prática docente, expressos nos Projetos Pedagógicos dos Cursos e Planos de Ensino.

O posicionamento da teoria-prática nesses documentos, frequência dos indicadores e sua forma de operacionalização apontam o seu grau de importância para a formação do aluno e refletem a formação docente no processo de articulação desses elementos nos componentes curriculares, na ótica oficial.

Os bacharelados formam profissionais para diferentes áreas de trabalho. As licenciaturas pretendem a formação docente, em especial para o ensino fundamental e médio, mas também para no nível superior. Entretanto, no ensino superior brasileiro, temos um percentual alto de bacharéis exercendo a docência, sem formação específica para essa finalidade, o que se reflete na atuação docente. $\mathrm{Na}$ instituição, centro universitário campo de pesquisa, temos 114 docentes, sendo 101 bacharéis $(88,60 \%)$ e 13 com licenciatura $(11,40 \%)$.

Para esta pesquisa, foram realizados levantamentos nos documentos mencionados e verificada a operacionalização desses elementos, teoria-prática, nos componentes curriculares dos cursos de Administração e Ciências Contábeis, bacharelado presenciais, confrontados/verificados nos discursos expressos nos Projetos Pedagógicos dos referidos cursos, e nos Planos de Ensino das disciplinas/unidades curriculares, elaborados por seus respectivos professores, em especial os componentes curriculares de caráter integrador como estágios supervisionados, trabalhos de conclusão de curso, produção intelectual e atividades de extensão comunitária e educacional.

As Diretrizes Curriculares Nacionais dos Cursos de Graduação estão expressas no Parecer CNE/CES 67/2003, aprovado em 11/03/2003, baseado na Lei de Diretrizes e Bases da Educação Nacional- LDBEN (Lei 9394/96) e no Plano Nacional de Educação (Lei 10.172/2001), dentre outros. Foram instituídas para substituir os currículos mínimos. As diretrizes estabeleceram seis princípios básicos, dentre eles, fortalecer a articulação da teoria com a prática (grifo nosso). A partir desses princípios foram criadas as diretrizes curriculares de cada curso, observando-se múltiplos perfis profissionais, diversidade de carreiras, integração do ensino de graduação com a pós-graduação e privilégio de competências intelectuais que refletissem heterogeneidade das demandas sociais. Em resumo, as Diretrizes Curriculares Nacionais, no referido parecer, "concebem a formação de nível superior como um processo contínuo, autônomo e permanente, com sólida formação básica e uma formação profissional fundamentada na competência teórico-prática (grifo nosso), de acordo com o perfil de um formando adaptável às novas e emergentes demandas" (p.6).

A Resolução no. 04, de 13 de julho de 2005, instituiu as Diretrizes Curriculares de Graduação em Administração, bacharelado. No que concerne ao objeto de estudo, articulação teoria-prática nos componentes curriculares, nos eixos ensino, pesquisa e extensão, essa resolução apresenta como um dos elementos obrigatórios no Projeto Pedagógico de Curso, no art. $2^{\circ}$., inciso $\mathrm{V}$ : a exigência de previsão dos modos de integração entre teoria e prática. Os conteúdos curriculares se distribuem em quatro campos de formação: básica, profissional, estudos quantitativos e suas tecnologias e complementar, não fazendo menção específica ao objeto em questão. O curso caracteriza-se por formar profissionais generalistas.

A Resolução no. 10, de 16 de dezembro de 2004, instituiu as Diretrizes Curriculares para o curso de graduação em Ciências Contábeis, bacharelado. Seguindo o mesmo raciocínio, observou-se que o Projeto pedagógico deverá abranger, dentre os elementos estruturais, no art. $2^{\circ}$. incisos $\mathrm{V}$ : $\operatorname{modos}$ de integração entre teoria e prática e no inciso XI: inclusão opcional de trabalho de curso, que deverão estar centrados em áreas teórico-práticas. Quanto às competências e habilidades exigidas, a resolução não se detém explicita e particularmente à relação teoria-prática. Entretanto, ao tratar dos conteúdos de formação refere-se aos campos de Formação Básica, Formação Profissional e Formação Teórico-Prática, especificamente referindo-se ao Estágio Curricular Supervisionado, Atividades Complementares, Estudos Independentes, Conteúdos Optativos, Prática em Laboratório de Informática utilizando softwares atualizados para a Contabilidade. Neste item, dois aspectos merecem destaque: os estágios poderão ser 
realizados na própria instituição de ensino mediante laboratórios e as atividades de estágio poderão ser reprogramadas e reorientadas, de acordo com os resultados teórico-práticos até que os resultados sejam considerados satisfatórios.

As atividades Complementares abrangem a prática de estudos e atividades independentes, transversais e opcionais, de interdisciplinaridade e ações de extensão junto à comunidade. O Trabalho de Conclusão de Curso é, entretanto, componente curricular opcional da instituição o que fragiliza a própria exigência legal. $\mathrm{O}$ que se constata é que mesmo apontando lacunas na articulação teoria-prática nos componentes curriculares, o curso de Ciências Contábeis aponta indicadores dessa relação em grau mais acentuado, embora deficitário, do que o curso de Administração.

Ao verificar-se a presença desses indicadores nos respectivos Projetos Pedagógicos de curso e Planos de ensino das disciplinas de caráter integrador, constata-se que, apenas o Projeto Pedagógico do curso de Ciências Contábeis contempla a articulação teoria e prática, no que diz respeito aos conteúdos curriculares e sua abordagem reflete a formação teórico-prática expressa nas Diretrizes Curriculares do curso. O que não ocorre com o Projeto Pedagógico do curso de Administração, em que não há uma preocupação expressa da articulação teoria-prática.

Em especial, no caso dos Estágios Supervisionados, observa-se que o curso de Administração propõe situação simulada, como pode-se verificar nas ementas de Estágio Supervisionado I (5.termo):" Descrição detalhada da empresa e dos principais processos administrativos. Elaboração e análise de fluxogramas operacionais do negócio. Elaboração dos layouts correspondentes aos fluxogramas" e Estágio Supervisionado II (6 $6^{\circ}$. Termo): "Tipos de pesquisa de mercado. Escolha de empresa. Enunciado do problema. Objetivo Geral. Objetivos Específicos. Metodologia. Técnicas de coleta de informações e amostra. Pesquisa de Campo. Tabulação dos resultados. Geração de tabelas e gráficos. Relatório de análise dos dados. Apresentação dos resultados", o que não ocorre com o curso de Ciências Contábeis.

No curso de Ciências Contábeis, embora o estágio se utilize de laboratório de informática, os alunos vivenciam situações concretas, utilizam dados reais fornecidos por outras disciplinas e os alunos executam atividades propostas, conforme ementas de Estágio Supervisionado I e II (5 $5^{\circ}$ e $6^{\circ}$. Termo): “Atividades pertinentes ao curso, intercursos e interdisciplinares, ligadas às organizações, integradoras do processo de formação do profisssional em Ciências Contábeis, realizadas em empresas públicas e/ou privadas, na Empresa Júnior Toledo-EJT, de acordo com o regulamento do estágio supervisionado obrigatório".

Ainda foram analisados os Planos de Ensino de outras disciplinas também com caráter integrador, em que a relação teoria-prática está presente, sem contudo, corresponder aos conceitos pressupostos de unidade dialética e práxis. São elas: disciplinas do curso de
Administração em que a articulação teoria prática se evidencia: Estágio Supervisionado I e II ( $5^{\circ}$ e $6^{\circ}$ termo); Jogos de Empresa ( $7^{\circ}$ termo); Desenvolvimento de Novos Negócios I e II ( $7^{\circ}$ e $8^{\circ}$ termo); Consultoria Empresarial ( $8^{\circ}$ termo). No curso de Ciências Contábeis temos: as Práticas Contábeis I até VI $\left(3^{\circ}\right.$ termo até $8^{\circ}$ termo); Consultoria Contábil II ( $8^{\circ}$ termo); Estágio Supervisionado I e II ( $5^{\circ}$ e $6^{\circ}$ termo); Análise das Demonstrações contábeis II ( $8^{\circ}$ termo); Auditoria Contábil II ( $8^{\circ}$ termo).

Quanto ao outro documento legal, utilizado para o confronto entre discurso oficial e articulação teoria-prática, acrescenta-se que o Instrumento de Avaliação de Cursos de Graduação presencial e a distância subsidia os atos autorizativos de cursos e são utilizados pelos avaliadores de cursos como referencial de oferta nas dimensões 1.Organização didático-pedagógica, 2.Corpo docente e 3.Infraestrutura. $\mathrm{Na}$ dimensão 1. Organização Didático-Pedagógica, pertinente a este estudo, observou-se que dos 27 itens, apenas 8 são relativos à teoria-prática, mas somente um faz menção à sua articulação, em diferentes graus e significados, nos bacharelados. É o item 1,5 que se refere ao indicador estrutura curricular, incluindo: flexibilidade, interdisciplinaridade, acessibilidade pedagógica e atitudinal, compatibilidade da carga horária, articulação teoria e prática.

Deve-se observar que o item 1.7 sobre Metodologia não explicita a relação teoria-prática.

Os itens $1.8,1.9,1.10$ e 1.11 dizem respeito ao Estágio. O item 1.8 , sobre Estágio Supervisionado Curricular (obrigatório), o foco não é a relação teoria e prática, mas a existência de convênios, formas de apresentação, orientação, supervisão e coordenação. Portanto, muito mais voltado para atendimentos burocráticos do que aprendizagem do aluno, na ótica da articulação teoria-prática. O item 1.9 refere-se ao Estágio Curricular para a Educação Básica, obrigatório para as licenciaturas, e não bacharelado. O item 1.10, que se refere ao Estágio nas Licenciaturas, o foco são as parcerias, acompanhamento, planejamento, desenvolvimento e avaliação. $O$ item 1.11 Estágio Curricular Supervisionado trata da relação teoria e prática (obrigatório para as licenciaturas e não se aplica aos demais cursos). Este é o item em que a articulação entre teoria-prática é mais evidenciada e complementa o item anterior.

Os dois itens subsequentes, Atividades Complementares e Trabalho de Conclusão de Curso-TCC, são relativos a atividades integradoras da teoria e da prática, mas não contemplam essa preocupação.

Por último, complementando a análise nos eixos pesquisa e extensão, observou-se que na pesquisa os cursos da área de negócios, onde se inclui os cursos estudados, fazem parte de um grupo de iniciação científica da IES intitulado: Relações Empresariais, Inclusão e Desenvolvimento Sustentável, supervisionado pelo Núcleo de Estudos e PesquisaNEPE. Entretanto, vale destacar a dificuldade que 
professores e alunos têm para produção intelectual. Nos Encontros de Iniciação Científica, anuais, a produção técnica é mais relevante em ambos os cursos.

Esses cursos apoiados pela Coordenadoria de Extensão e Assuntos Comunitários-CEAC, com o objetivo de promover e incentivar a integração da comunidade acadêmica com a comunidade regional, apresentam experiências, dados e informações que contribuem para a melhoria das atividades acadêmicas. Os alunos dos dois cursos participam de Programas de Extensão que abrangem: a) Projetos de extensão: Coleta de Preços e Índice de Preços Toledo (Empresa Junior); b) Educação Continuada; c) Atividades Acadêmicas e Prestação de Serviços (Jornada de Cinema); d) Assuntos Comunitários (Coleta Seletiva de Lixo, Doação de Sangue, Cadastro de doadores de medula). A extensão permite a integração intercursos e amplia a relação da comunidade acadêmica com a local e regional.

Embora exista, muitas vezes, busca pela articulação teoria-prática, isso ainda não ocorre em conformidade com os pressupostos conceituais tomados como referência, a formação docente nessa direção e as exigências legais, pois os documentos oficiais não se preocupam com essa articulação.

Para que se efetive a articulação teoria-prática nos componentes curriculares pelos professores, não basta formação profissional de qualidade, deve-se considerar a intencionalidade docente nessa direção e sua relação com a conscientização. Para Coll (1996, p.319), a intencionalidade está na raiz do processo educativo, determina as mudanças que se quer provocar no aluno e o rumo do seu desenvolvimento.

Freire vai além "A conscientização não é somente conhecimento e reconhecimento do objeto cognoscível, é opção, decisão, compromisso" (FREIRE, 2003, p.10). Pode-se afirmar que, segundo Heller (2000, p.20) o desenvolvimento da consciência permite ao sujeito utilizá-la intencionalmente, possibilitando a superação de ações cotidianas, do senso comum em direção às não cotidianas, pertinentes à ciência, política, arte, filosofia, afetas às necessidades exigidas nas aprendizagens mais complexas, no ensino superior.

\section{Indicadores e Possibilidades - Considerações finais}

Nas sociedades contemporâneas, caracterizadas pelo movimento, mudanças e indefinições, ganham espaço as relações, as articulações, a dialogicidade e as interlocuções. É nesse contexto que se discute a análise de fundamentos epistemológicos da articulação teoria-prática nos componentes curriculares, à luz dos documentos legais pertinentes e sua relação com a formação docente, considerando-se a posição estratégica do professor para que se efetive essa articulação.

A ausência de articulação teoria-prática nos componentes curriculares evidencia a distância entre as demandas sociais, currículos responsivos e formação docente.

A pesquisa e a análise sobre a articulação teoria-prática nos componentes curriculares supõem a relação teoria e prática como uma unidade dialética. Portanto, a articulação e a integração entre teoria e prática ocupam espaço relevante nos componentes curriculares dialógicos e relacionais, de caráter integrador. $\mathrm{O}$ processo se coloca como elemento vertebrador nos currículos atuais.

Ao se confrontar a presença da teoria e da prática nos discursos oficiais, Diretrizes Curriculares Nacionais e Instrumento de Avaliação de Cursos de Graduação, com a prática docente, verifica-se que poucos são os itens desses documentos que se referem à teoria e à prática, e a articulação entre eles está explicita em apenas um item. Essa articulação aparece sugerida, apenas, nos Projetos Pedagógicos e ou Planos de Ensino, documentos institucionais, quando se referem a determinados componentes curriculares.

Os documentos relativos, tanto aos cursos estudados como aos de licenciatura, prescrevem muito mais conteúdos teóricos do que prática, como legado do pensamento que predominou durante tempos, de que a ciência determinava a sociedade e não o inverso como se constata hoje (CUNHA, 2003, p.68-70). Os componentes curriculares das matrizes estudadas demonstram os estágios curriculares supervisionados, bem como projetos integradores e práticas profissionais colocadas nas séries finais dos cursos, resquícios de uma visão tradicional, positivista, resultando em componentes curriculares isolados, fragmentados sem a devida articulação neles e entre eles.

Essa interlocução é muitas vezes tentada por meio de atividades interdisciplinares, o que nem sempre supera essa fragmentação, pois as causas também podem estar na formação docente pessoal e profissional, nível de intencionalidade do professor no ato educacional direcionado para esse fim, bem como variar de acordo com as possibilidades garantidas pelo contexto institucional em que atuam, por meio de cursos de capacitação e ou apoio financeiro para essa finalidade.

Outra questão a ser destacada é em relação à concepção de prática e práxis. O que se constata é que predomina a prática pela prática e não a práxis, prática consciente que se espera do professor, o que pode se colocar como entrave para a articulação entre teoria-prática.

Verifica-se, por último, que há uma fragilidade pronunciada, quase ausência, em relação ao que se espera dos processos relacionais e de articulação, intrínsecos aos componentes curriculares, observados no descompasso entre o lócus de formação desses profissionais (matrizes curriculares de acordo com as DCN) e o lócus de atuação docente (escola); em lacunas no entendimento desses professores quanto à concepção de teoria-prática como unidade dialética; presença de resquícios positivistas, em especial nos componentes integradores, estágios, produção intelectual e nas atividades de extensão.

A intencionalidade docente se coloca como possibilidade de superação dessa dicotomia existente entre teoria e prática, pois está relacionada ao nível de conscientização do professor para além do senso comum (HELLER, 2000) e uma sólida formação do professor, o que supõe desenvolvimento de competências e habilidades voltadas para mudança, em especial senso crítico-reflexivo, flexibilidade e 
criatividade para inovar e que corresponda às demandas sociais que exigem aprendizagem permanentemente responsiva.

\section{Referências}

Bauman, Z. A face humana da sociologia. O Estado de São Paulo, 30 abril 2011, disponível em http://cultura.estadao.com.br/notícia s/geral, a face-humana-da-sociologia-imp.712848

Bogdan, R. C. Investigação qualitativa em educação. Poro: Porto Editora, 1994.

Coll, C., Palacios, J., Marchesi A. (Org.) Desenvolvimento psicológico e educação. Porto Alegre: Artes Médicas, 1996. v 2.

Cunha, M.I. Formação de professores e currículo no ensino superior. Reflexões sobre o campo político-epistemológico. In: Moraes, C., PACHECO, J.A., Evangelista, M.O. Formação de professores. Perspectivas educacionais curriculares. Coleção Currículo, Políticas e Práticas. Porto: Porto Editora, 2003.

Diretrizes Curriculares Nacionais-DCN. Parecer CES/CNE 67/2003, aprovado em 11/03/2003.

Diretrizes Curriculares Nacionais do Curso de Graduação EM Administração. Resolução CES/CNE, no. 04, de 13/07/2003.

Diretrizes Curriculares Nacionais DO Curso de Graduação em Ciências Contábeis. Resolução CES/CNE no. 10, DE 16/12/2004.

Freire, P. Pedagogia do oprimido. 37. ed. São Paulo: Paz e Terra, 2003.

Freire, P. Pedagogia da Autonomia: saberes necessários à autonomia. 29ed. São Paulo: Paz e Terra, 2004.

Freire, P. Professora sim, tia não: cartas a quem ousa ensinar.16. ed. São Paulo: Olho d'água, 2006.

Freire, P.; SHÖR, Ira. Medo e ousadia: o cotidiano do professor.11. ed. Rio de Janeiro: Paz e Terra, 2006.

Gamboa, S. A dialética na pesquisa em educação: elementos de contexto. In: FAZENDA, I. (Org.). Metodologia da pesquisa educacional. 4. ed. São Paulo: Cortez, 1997. p. 91-115.

Giroux, H.A. Os professores como intelectuais: rumo a uma pedagogia crítica da aprendizagem. Porto Alegra: Artes Médicas, 1997.

Gonçalves, Y.P. Qualidade oficial, indicadores do MEC. In: Coimbra, C.L. et al (orgs). Qualidade em Educação. Curitiba/PR: Editora CRV, Série Currículo: Questões Atuais, vol 4, 2011.

Heller, A. O cotidiano e a história. 6. ed. São Paulo: Paz e Terra, 2000.

Instrumento De Avaliação De Cursos De Graduação Presencial E A Distância. Ministério da Educação. Instituto Nacional de Estudos e Pesquisas Educacionais Anísio Teixeira-INEP. Brasília, março de 2015.

SANTOS, B. de S. Um discurso sobre as ciências. São Paulo: Cortez, 2003. 